\title{
Preserving rapid prototypes: a review
}

CrossMark

\author{
Carolien Coon ${ }^{1 *}$, Boris Pretzel ${ }^{2}$,Tom Lomax ${ }^{3}$ and Matija Strlič ${ }^{1}$
}

\begin{abstract}
Rapid Prototyping (RP) has revolutionized the world of manufacturing. It has gained popularity among designers and artists, having developed from a visualization tool to a manufacturing tool for end-use products. Rapid-prototyped objects are being accessed by museums and the technology is being adopted for conservation applications. The review identifies the current most commonly used polymer based RP technologies and materials that are likely to enter museum collections, and formulates informed research topics related to their conservation. A knowledge exchange project was conducted with artists and designers using the technology via an online survey and interviews. The main technologies and materials used by artists and designers were identified and investigated including research that has been done into the stability of RP manufactured objects. Since these may be uniquely postprocessed by artists and designers, RP objects are often irreplaceable, i.e. cannot simply be reprinted. The evolution from rapid prototyping (RP) to additive manufacturing (AM) has resulted in extensive research into the mechanical properties and short-term stability of prototypes. However, very little research has been conducted into RP from the conservation perspective particularly long-term stability studies. Since RP technology is rapidly developing, it is crucial that conservators and scientists follow and inform these developments.
\end{abstract}

Keywords: Rapid prototype, Technologies, Materials, Conservation, Museums, Public engagement, Polymer degradation

In all the arts there is a physical component which can no longer be considered or treated as it used to be, which cannot remain unaffected by our modern knowledge and power. For the last twenty years neither matter nor space nor time has been what it was from time immemorial. We must expect great innovations to transform the entire technique of the arts, thereby affecting artistic invention itself and perhaps even bringing about an amazing change in our very notion of art.

- Paul Valery: Pièces sur l'art, La conquête de l'ubiquité

\section{Background}

The opening citation of Walter Benjamin's Art in the age of Mechanical Reproduction by Paul Valery [1], seems strangely relevant today with the advent of digital design and additive manufacturing (AM).

\footnotetext{
*Correspondence: carolien.coon.12@ucl.ac.uk

${ }^{1}$ Institute for Sustainable Heritage, University College London, London, UK

Full list of author information is available at the end of the article
}

The expiration of patents has led to rapid development of technologies used for rapid prototyping (RP) during the last 25 years (Table 1). Initially reserved for industry, the technologies have become more accessible and hailed as a 'manufacturing revolution'. At the forefront of experimentation, artists and designers were quick to adopt the technology for end products and rapid prototype artefacts soon achieved cult status and are entering museum collections [2]. Early prototypes are documents of this manufacturing revolution or 'maker movement' and may need to be preserved.

The terms 'layered manufacturing' and 'rapid manufacturing' are generally seen as synonymous with 'additive manufacturing' [3], while 'rapid prototyping' (RP) refers to the production of usually single items (prototypes) using AM technologies. However, AM currently still predominantly use systems that were developed for RP. Since most artworks and designs are in a sense 'prototypes', we will use the term 'rapid prototyping' to refer to AM technologies used for the purpose of artistic expression and conservation. It should be noted that the other blanket term that is often used, '3D printing', actually refers to a 
Table 1 Summary of polymer-based rapid prototype technologies, currently commonly used by artists and designers

\begin{tabular}{|c|c|c|c|}
\hline System & ASTM terminology & Common patented systems & Base Materials \\
\hline Solid based & Materials extrusion & $\begin{array}{l}\text { Fused deposition modelling }\left(\text { FDM }^{\circledR}\right) \\
\text { Patent: US5121329 A } \\
\text { Stratasays Inc. } \\
\text { Eden Prairie MN }\end{array}$ & $\begin{array}{l}\text { Acrylonitrile butadiene styrene (ABS), poly(lactic) acid } \\
\text { (PLA), polyethylene terephthalate (PET), polyvinyl } \\
\text { alcohol (PVA) }\end{array}$ \\
\hline \multirow[t]{3}{*}{ Powder based } & Binder jetting & $\begin{array}{l}\text { ZCorp 3D printing technology (3DP } \mathbf{P}^{\mathrm{TM}} \text { ) } \\
\text { Patent: US5204055 A } \\
\text { Massachsets Institute of Technology (MIT) } \\
\text { 3D Systems Ltd. } \\
\text { Rock Hill SC USA }\end{array}$ & $\begin{array}{l}\text { Plaster based powder, ink/water binders infiltrated } \\
\text { with epoxy, wax or cyanoacrylate }\end{array}$ \\
\hline & & $\begin{array}{l}\text { Voxeljet AG } \\
\text { Patent:US20110308755 A1 } \\
\text { Voxeljet Technology } \\
\text { Augsburg-Lechhausen, Germany }\end{array}$ & Foundry sand/acrylic polymer \\
\hline & Powder bed fusion & $\begin{array}{l}\text { Selective laser sintering }\left(\mathbf{S L S}^{\circledR}\right) \\
\text { Patent: US4863538 A } \\
\text { The University of Texas } \\
\text { 3D Systems Ltd. } \\
\text { Rock Hill SC, USA }\end{array}$ & $\begin{array}{l}\text { Polyamide (PA), acrylonitrile butadiene styrene (ABS) } \\
\text { metals }\end{array}$ \\
\hline \multirow[t]{2}{*}{ Liquid based } & Materials jetting & $\begin{array}{l}\text { Polyjet }^{\mathrm{TM}} \\
\text { Patent: US6259962 } \\
\text { Objet Geometries Ltd } \\
\text { Stratasays Inc. } \\
\text { Rehovot, Israel }\end{array}$ & $\begin{array}{l}\text { Proprietary acrylics, acrylates and epoxy thermoset } \\
\text { plastics }\end{array}$ \\
\hline & Vat photo-polymerisation & $\begin{array}{l}\text { Stereolithography }\left(\mathbf{S L A}^{\circledR}\right) \\
\text { Patent: US4575330 } \\
\text { UVP Inc. } \\
\text { 3D Systems Ltd } \\
\text { Rock Hill SC, USA }\end{array}$ & \\
\hline
\end{tabular}

specific AM technology and should not be used to refer to RP in general [3].

Museums and heritage institutions themselves have embraced the technology, using it for conservation, education, public engagement and to increase access to collections. The British Museum (through Sketchfab), Smithsonian (through Six3D) and MOMA (through Thingiverse) already allow digital access to their collections for home printing. The Prado, with their exhibition: Hoy toca el Prado, collaborated with Estudios Durero to unlock the world of painting to visually impaired visitors and to offer regular visitors a multi-sensory experience [4]. Such experiences allow for more intimate interaction with collections resulting in better cognition, recollection and experience [5].

The transgression from the real world to the virtual and back has been coined 'dancing the flip flop' as fidelity to the original is not the aim, but instead "weird things" should "happen on the walls between worlds" [5, 6]. By hosting 3D Printing 'Hackathons' museums such as MOMA provide the opportunity to the public to dance the flip flop with objects in their collection, encouraging close scrutiny and a creative opportunity through digital manipulation, deepening their emotional relationship with the collection $[5,7]$.
3D printing is being extensively used to interact with visitors as the following examples described by Neumiller et al. [5] demonstrate. Faces of ancient Egyptians were reconstructed on prototyped sculls [8] at the Redpath Museum in Montreal, Canada, and in Leicester, UK, the skeletal recovery of Richard III was accompanied by a reconstruction of what the last Plantagenet King might have looked like [9]. The Derby Museum, UK, engaged the local community in their Re:Make programme by including them in the design process for displays during refurbishment of the Silk Mill building using 3D Printing [5]. The ever decreasing costs have allowed makerspaces to become extensions of traditional art workshops often held in museum education departments [7].

Beyond engagement, 3D scanning and RP have been successfully used for research. In archaeology, making tangible objects from 3D virtual data has helped in analysis [10]. Notable examples are the reconstruction of a medieval skull without the need for contact of original material with adhesives or mould making materials [11] or on a larger scale, the reconstruction of a medieval ship served to aid in understanding the construction, as a model for restoration and for public engagement [12]. In conservation, the technology has been used for replacement parts for objects [13]. In 2013, the International Institute 
for Conservation held a workshop at the University of Amsterdam on 3D scanning and 3D printing to train conservators in the use of RP for conservation applications.

As in digitization more generally, replicas can be printed to conserve a fragile original, or to remove the need for the historic objects (or visitors) to travel. In the project Conserving by copying: 3D Printing Tutankhamun's Tomb using photographs taken in 1922 by Harry Buton, a replica of the intact tomb was recreated a mile away from the original in Luxor, thereby relieving the tomb of stresses from visitors who actually preferred viewing the replica $[14,15]$. There are challenges related to surrogates such as the lack of 3D colour printing standards as is the Pantone code [5]. 3D printing offers great possibilities but leads to 'multiplicated' collections, with sustainability issues arising from the need for storage, care and disposal of such collections.

3D artworks and designs could be considered as 'digitally born' cultural heritage, with the associated issues related to data management, conservation and migration, an issue beyond the scope of this paper but well summarized by Karp [16].

Rapid prototyping can involve a range of materials, such as metals, ceramics, polymers or composites. It is the polymers that will, with all likelihood, turn out to be the least stable: while polymer objects have only recently achieved cultural heritage status, our experience of conserving them is much shorter than with traditional artifacts, many of which have already withstood the test of time [17]. The instability of many early synthetic and semisynthetic materials is now becoming manifest and posing significant conservation challenges, and it is likely that the teething issues with early RP technologies will become apparent in the near future. The range of materials and combinations of materials (composites) used is increasing rapidly and as noted by Neely in 2014 [7], the technology is progressing too fast to leave enough time to assess it.

According to Albus et al. [18] the industrial standard for 'long-life plastics' is to have a life expectancy of 15-25 years, but as early RP materials were not designed to this standard, it is possible that their life expectancy will be even less. The drive towards green manufacturing as a result of regulations of emissions may lead to further rapid development of RP technologies to decrease their environmental footprint. As Drixo and Pegna [19] note "...new materials should not be allowed to reach the market before demonstrating their compliance with environmental regulations." There has been valuable research in recent years into the conservation of 'traditional' heritage polymers $[20,21]$; however, RP polymers are extremely diverse and complex both compositionally and from the viewpoint of variable manufacturing parameters, and thus require independent study. Despite some RP polymers being chemically identical to plastics already known and researched by conservators, such as Acrylonitrile Butadiene Styrene (ABS), the different forming procedures applied to them can impact their material stability. The situation is further complicated by the development of materials which mimic the properties of 'traditional' engineering polymers such as Digital ABS from Polyjet, a photopolymer which differs chemically from traditional ABS [22].

In Fig. 1, it is possible to appreciate extensive colour changes induced in six different RP materials during a photoageing experiment designed to engage the public with conservation and research issues related to RP. The design considerations and experimental conditions are described in the Additional file 1 . Additional file 2 is the digital artwork used for printing which is also available in .ply and stl formats in Additional files 3 and 4 to download for printing.

To conserve RP artworks it is necessary to have an understanding of the process of creation, the different technologies involved, the materials used as well as their chemical and mechanical properties. Research specifically dealing with conservation issues related to rapid prototypes is sparse [2, 23, 24]. In this paper we therefore review the state-of-the-art of RP manufacturing using polymers, and discuss conservation concerns as identified by artists and designers, to inform the emerging research questions.

\section{Artists' and designers' views}

In order to explore the conservation issues that may have already arisen and could inform directions for future research, we sought the views of artists and designers themselves in the first instance. In 2013, a knowledge exchange project with 54 artists and designers was initiated through an online survey and interviews to identify to following:

- Main rapid prototype technologies and materials used

- Issues related to digital archives, software and hardware

- Issues related to the ageing of prints

- Attitudes to authenticity and replication of artworks

- Attitudes to conservation

Invitations to partake were posted on social media and sent directly to 117 artists and designers. Forty seven online survey responses were obtained, of which 44 were complete. Ten artists and designers agreed to be interviewed. Participants were asked how to best describe themselves at the start of the survey and interviews: the responses included sculptors, craftsmen, architects, product designers, jewellery and fashion designers. For analysis, these were grouped into designers and artists. 


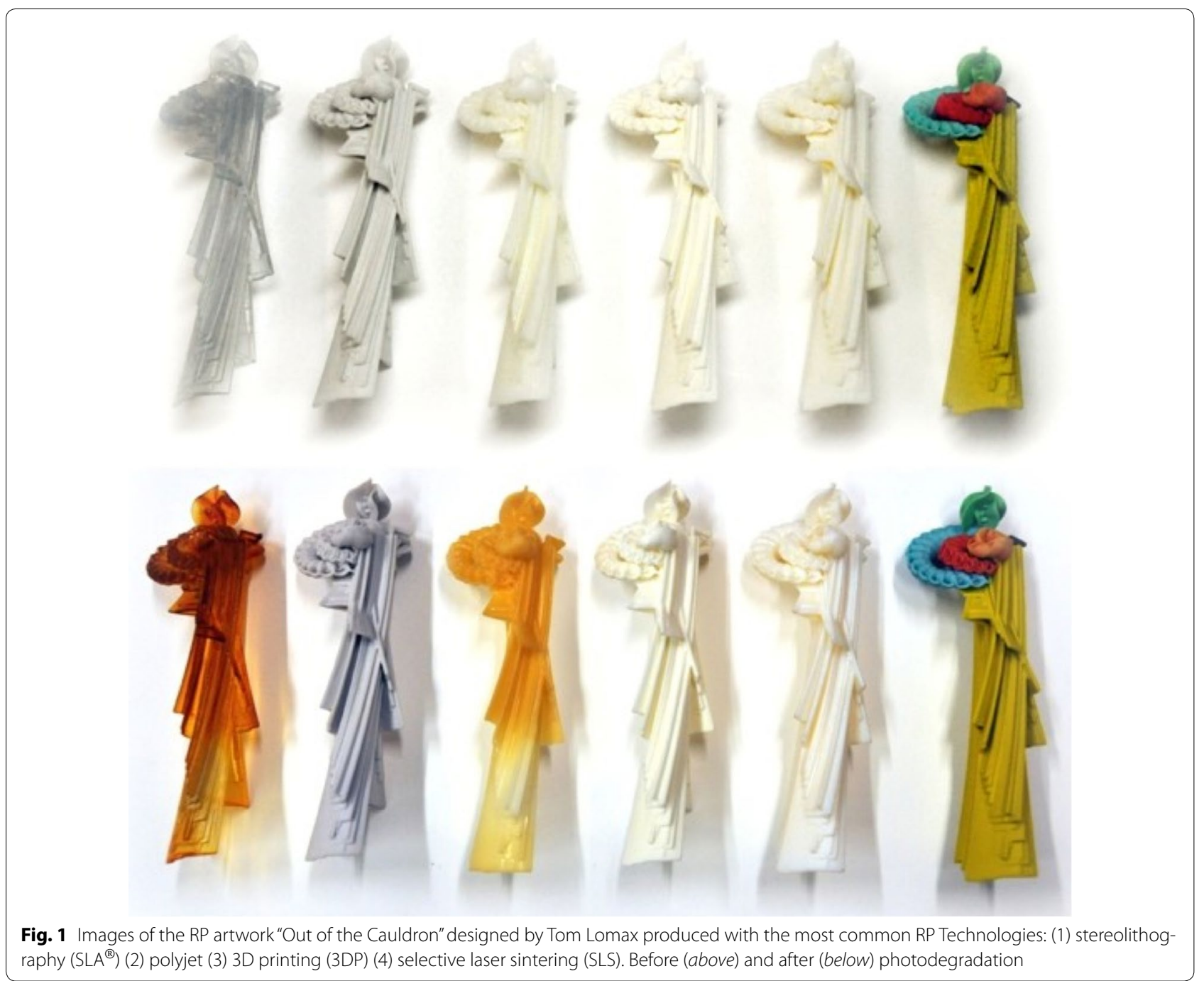

Craftsmen, architects, jewellery and product designers were all grouped under designers and sculptors under artists. Three respondents identified their practice as both art and design. Their responses were included in the overall survey analysis but ignored in comparisons between artist and designers.

Selective Laser Sintering $\left(\mathrm{SLS}^{\circledR}\right)$ and Zcorp 3D Printing $\left(3 \mathrm{DP}^{\mathrm{TM}}\right)$ were identified to be the two main technologies used by participants (65 and $59 \%$ respectively). $\mathrm{SLS}^{\circledR}$ was found to be more popular among designers and Zcorp 3D Printing among artists, and both preferred to use printing bureaus for printing. Artists generally developed close working relationships with the bureau of choice, and heavily relied on their advice in relation to RP material choice. Stereolithography $\left(\mathrm{SLA}^{\circledR}\right)$ and PolyJet Technology (43 and $30 \%$ respectively) both employ photopolymers making photopolymers the most common RP material used by participants.
The participants were well aware of issues related to software obsolescence. The majority (68\%) thought the physical print was more valuable than the digital design, which indicates that conservation of the print should take priority over the digital archive.

I prefer the original artefact, because I think, that: that was that moment in time.

- Geoff Mann

When you are going to reproduce them I would lose the control, that means that there could be a big difference between the piece that is presented, the reproduction could be different from the original. - Luc Merx

I cannot replicate the piece anymore, because technology has gone so far that it knows when it is doing 
something wrong. So it fixes it, but what I was interested in was, well, when the laser hit a reflective object it almost bounces, it spikes back out, because it can't tell the difference between what's a real material object and what reflection is, it counts reflection as a material, I found that very interesting.

- Geoff Mann

If you've got works on tape from PCs or silicon graphics workstations from the nineties then you cannot get that information off anymore or it certainly wouldn't be easy to or be at great cost, I'm sure. It's one thing that worries me about my own work because I've got literally hundreds and hundreds of fine art sculptures on disks that obviously, because of the expense of production as well, they'll remain on disc until such time as they can be printed and so I'm hoping to archive them away...so every now and again somebody comes up with a fine new idea that's faster, cheaper and better and suddenly you find that all of your archived material is then redundant. It's obsolete. You can't retrieve it any more.

- Keith Brown

A good majority of $81 \%$ have noticed a physical change in their prints over time. Considering that the technology is still in its infancy, these changes have occurred and become noticeable within a few years. Surprisingly, and perhaps in contradiction to the previous finding on the value of the physical print, $84 \%$ of participants indicated that if a work becomes damaged or broken then they would be happy for the work to be reprinted. Discolouration was a commonly noticed type of change and it was found to be more acceptable with artists, who tended to view it as a form of 'patina'.

I was very much interested in the change of colour, in the change of the material and I always try to get to the point that they just accept that it is not the same as the digital file and that they accept that the change of the colour is one of the main qualities of those resins... I would be very happy if the change of colour is just accepted the way it happens. I think this is a problem of today's design and architecture that the designer ignores the material, for me it is very clear that the design should react on the colour changes and that it is a problem of the design if it does not work anymore.

- Luc Merx

When I did a prototype of the object it discoloured incredibly quickly you know it started to yellow incredibly quickly and I actually set up a series of tests where I put one in more sunlight and one in shade just to see how they deteriorate and actually

aesthetically I quite like that visual kind of thing.

- Mat Chivers

$75 \%$ of participants were happy to supply museums with digital copies of their work, provided that there was a copyright clause in place, but not to private collectors. A concern was raised during interviews that there is no way of limiting copies or editions which in turn would impact on the value of the artwork.

Of all the respondents, $84 \%$ would like conservators to liaise with them regarding conservation of their work. This is clear guidance for conservators to be in a dialogue with artists when establishing best practice for the care of rapid prototype collections especially since technological developments may soon render some current systems as obsolete.

The technology, and the artistic and business practices surrounding it, are changing so fast that every model produced that way is unique not just as a design, but as a historical moment. Is that kind of thing worth recording or conserving? Not for me to say, but since in a personal way I think something of millennial importance is going on here, I'm very glad to hear someone's considering the question.

- Bathsheba Grossman

$81 \%$ of artists and $42 \%$ of designers in the study manually finished work after printing. A variety of materials are being applied for protection, aesthetics or in preparation for casting in other materials. Post-processing techniques included sanding, electroplating, flocking and spraying with commercially available lacquers and coatings. Random glitches in the technology are often used as part of the artwork which would be impossible to replicate. Artistic manipulation of the work after printing raises ethical problems regarding replication and means that a print should be regarded as unique, and not as a replaceable 'consumer' product.

\section{Rapid prototyping: an overview}

Initiated by Charles Hull's invention of Stereolithography $\left(\mathrm{SLA}^{\circledR}\right)$ in 1984, rapid prototyping (RP) has revolutionized the design and manufacturing industries. Designers can easily visualize products and make adjustments before manufacturing, thus reducing time-to-market and thereby cutting costs [25]. Previously, skilled artisans would have to spend weeks crafting prototypes by hand [2]. Any necessary alterations would add additional weeks to production. With rapid prototyping flaws in the design can be detected quickly and easily altered early in the production cycle. The risk of waste is significantly reduced, particularly if undetected flaws led to the production of faulty products [26]. 
Chua and Leong give detailed descriptions of various RP technologies [27]. However, what all RP processes however have in common is layered fabrication of threedimensional models directly from cross-sectional digital design data. The design model is converted into a STL digital file, the stereolithography file format, developed specifically for computer-aided design software which allows users (through vector-based graphics) to design and visualise models in 3D. The object is then 'sliced' into two-dimensional cross-sectional data. The physical objects are 'grown' by building up the cross-sections layer by layer (Fig. 2). For this reason, the term layered manufacturing (LM) has also been used.

Since the advent of stereolithography there has been a surge in the development of different RP technologies, which have been patented and commercialized. Some of these may have already become obsolete [28] as could be concluded from comparison of the early technology reviews by Pham et al. [26] and Yan et al. [29], or they may have been experimental and remained undeveloped beyond the research phase; or are now known by different names. For example, Photo Masking (PM) described in 2010 by Chua et al. [30] appears to be similar to that of
Solid Ground Curing (SGC) which according to Levy et al. [28] disappeared from the market in 1999. The annual reports published by Wohlers and Associates are useful to keep track of developments [31,32]. Their summary on the history of RP reflects the competition between suppliers of RP technologies, and lists suppliers and manufacturers of RP systems, which have ceased to trade [32].

However, the majority of systems are only variations of six principal RP technologies, which can be further grouped into (i) liquid based systems, (ii) solid based systems and (iii) powder based systems [25]. In 2012, the ASTM International Committee F42 on Additive Manufacturing Technologies approved the standard terminology which has recently been reviewed and adopted by the British International Standards Institution [33]. Table 1 summarizes these terminologies along with proprietary names and materials of the polymer-based RP systems which include: Stereolithography (SLA), Selective Laser Sintering (SLS), Fused Deposition Modelling (FDM) and 3D Printing $\left(3 \mathrm{DP}^{\mathrm{TM}}\right)$. A short description on Polyjet ${ }^{\mathrm{TM}}$ will also be included under Stereolithography, as it appears to be the leading platform for high-resolution three-dimensional printing [30].

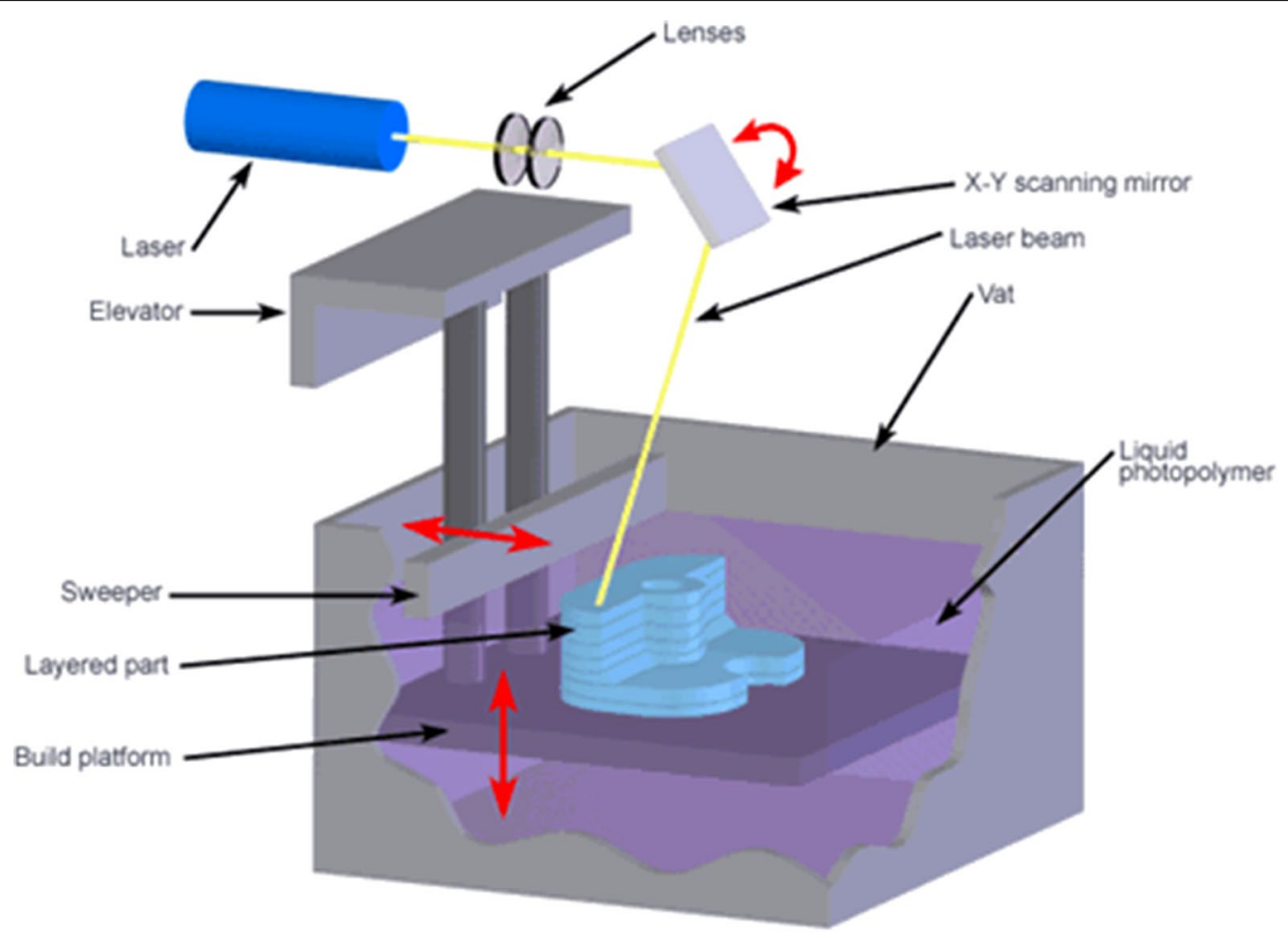

Copyright 02008 CustomPartNet

Fig. 2 Scheme of SLA ${ }^{\circledR}$ layered manufacturing. Reproduced from CustomPartNet with permission 


\section{Material properties and degradation}

In-depth research into the material properties and building processes of rapid prototypes only started once RP technologies were considered for production of end-use products ('rapid manufacturing').

As a heritage material, semi-synthetic and synthetic polymers are relatively young and so is the study of their degradation in the cultural heritage context. The main focus in heritage science has been plastic materials in collections needing urgent attention due to rapid degradation, such as PVC, rubber, polyurethanes, cellulose nitrate and cellulose acetate $[21,34]$. The degradation mechanisms of plastics are as varied as the different plastic formulations, but there are common features in the processes of polymer degradation [34] with the typical pathways of degradation being hydrolysis, photolysis, thermolysis and oxidation, which can be further differentiated as photo and thermal oxidation. These reactions are due to chemical reactions of plastics with oxygen, pollutants, water, metal ions, light, heat, or any combination of these. Chemical degradation reactions cause structural changes within the polymer such as cross-linking, chain scission, and the production of chromophores and polar groups [21]. Due to environmental control in museums (UV filtering, $\mathrm{RH}$ and temperature) one would expect typical degradation pathways to be those involving oxygen (thermo/photo-oxidative reactions), however due to weak sites or impurities such as metal ions present in a polymer, thermolytic initiation of degradation of some polymers (PMMA, PVC) can occur. In the case of RP, as a result of various processing parameters it cannot be ruled out for photolytic initiation to occur via Norrish Type I or II reactions due to the presence of oxidised structures, unsaturated carbonyl $(\mathrm{C}=\mathrm{O})$ or $\mathrm{C}=\mathrm{C}$ groups introduced during synthesis and processing $[35,36]$.

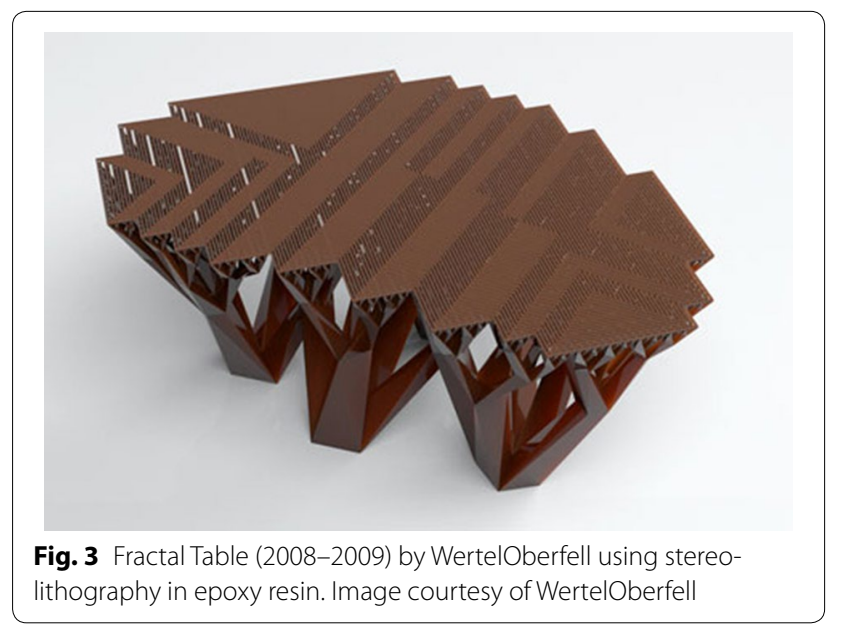

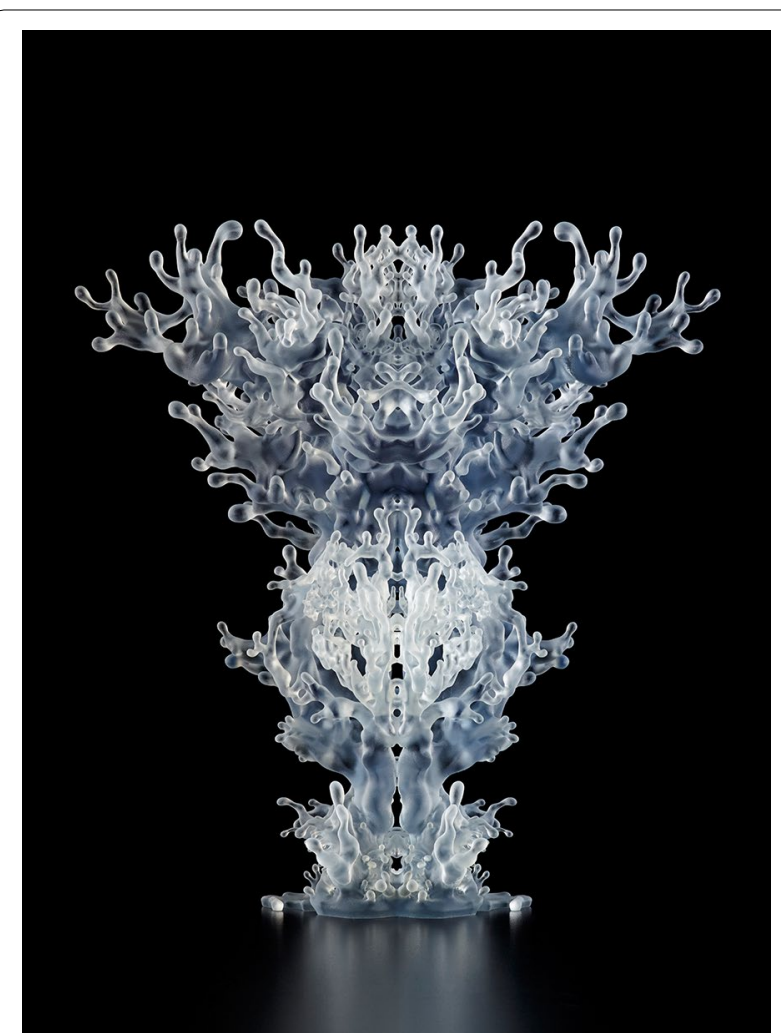

Fig. 4 Myrstaw (2014) by Nick Ervink, printed on a Stratasys Objet500 Connex3 Multi-material printer in VeroClear resin. Image courtesy of the artist

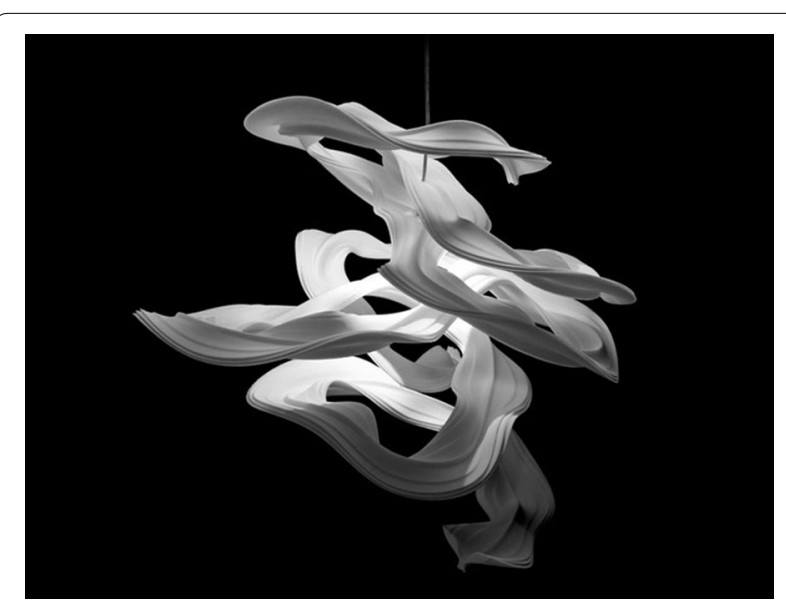

Fig. 5 Attracted to Light (2005) by Geoff Mann, laser sintered nylon. Image courtesy of the artist

Degradation of traditional art and heritage materials has always been more accepted than that of plastics, which are often considered valuable only if in pristine condition, particularly in the art market [18]. A level of acceptance to discolouration, depending on the age of 


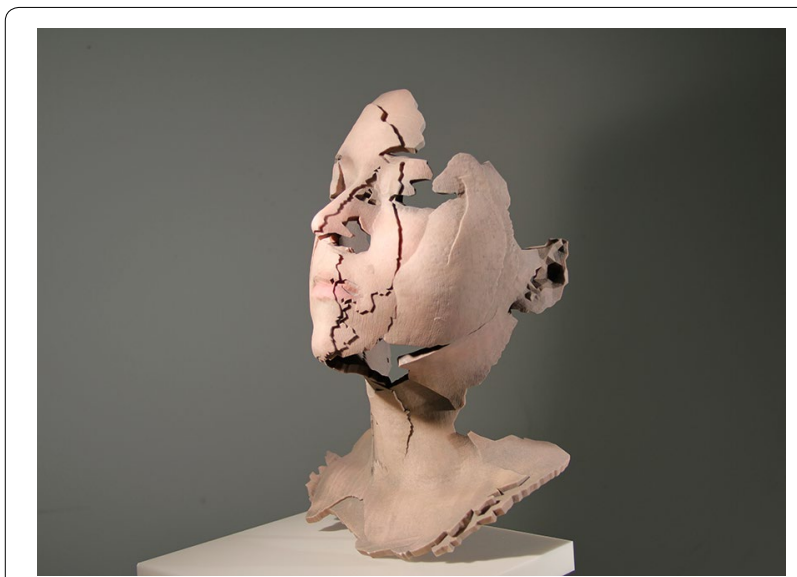

Fig. 6 Laura: RGB (2011) by Sophie Kahn. Full colour 3D print. Image courtesy of the artist

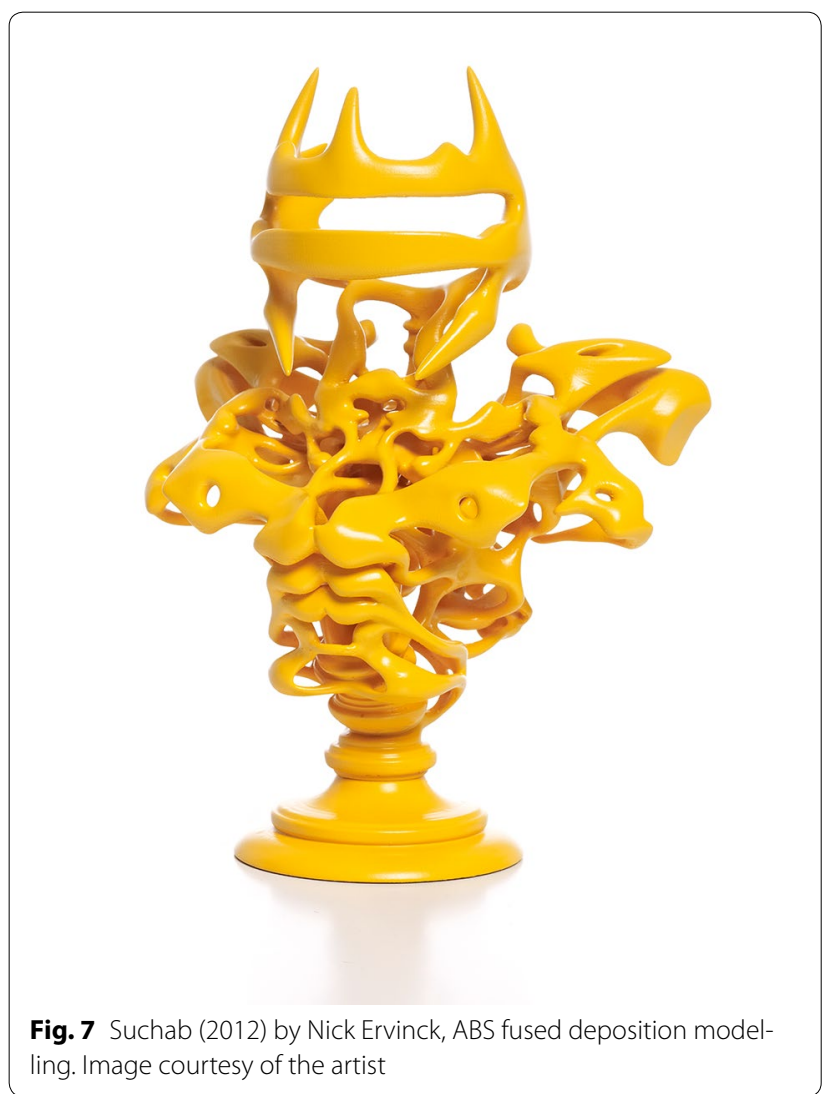

plastics is developing as seen amongst the participants in our survey ("Artists' and designers' views" section), some calling it patina. Even for collectors of vintage plastics 'patina' is now considered evidence of authenticity and originality [18]. However, unlike surface patinas on metals which provide a protective layer, the 'patina' on the surface of plastics is indicative of chemical degradation such as oxidation, which once initiated on the surface will proceed via a chain reaction into the bulk of the polymer [37]. In museums, objects attain a heritage status as their use changes from mechanical/functional to display, and aesthetic properties may take priority over mechanical.

The sections to follow review research into RP with regards to five main technologies utilising polymers, material properties, building parameters and ageing. Often only the base polymer is known for RP materials, and as with the 'traditional' polymers, degradation can be highly dependent on the presence of additives. Therefore, treating RP materials as a family of materials could be seen as oversimplification. However, as we will see, even with the small amount of published research on RP materials, similarities in behaviour are starting to emerge. For detailed reviews of base polymer degradation, the reader is referred elsewhere $[20,21,34,38]$.

\section{Liquid based systems}

Stereolithography (SLA $\left.{ }^{\circledR}\right)$

Stereolithography (SLA) is currently the most established rapid prototyping process (Fig. 3). It produces dimensionally accurate prototypes and as a result, has been the most widely used process in the industry [25, 29].

A prototype is built up from cross-sectional data obtained from the stereolithography file (STL), which is the standard format for all RP technologies. The prototype is built on a platform in a vat of photo curable resin. The platform is lowered to just below the surface of the resin to a depth suitable for sufficient laser penetration. The model is built in layers by scanning and curing the surface of the liquid photopolymer with lasers which have UV output. Initially, He-Cd (325 nm) or Ar Ion lasers $(351 \mathrm{~nm})$ were used but developments in the last 10 years in laser technology and since the evolution from RP to RM, diode-pumped, solid-state, Q-switched lasers are increasingly being used, typically emitting at $355 \mathrm{~nm}$ with output powers from 0.5 to $2 \mathrm{~W}$ and a pulse-width in the $10-30 \mathrm{~ns}$ range [39-41]. First the contours are scanned corresponding to the cross-section, then scanning of a hatch pattern fills in the rest. The polymerization process is photoinitiated, leading to the formation of a solid layer. The platform is then lowered to the same depth below the resin surface, enough for one layer of resin to be swept across and scanned. The liquid resin does not provide any structural support and in the case of overhanging parts, structures have to be built in for support. After printing is complete, the model is only $95 \%$ cured and referred to as 'green', the model then has to be washed in a chemical bath (isopropanol) and then post-cured by exposure to broad-spectrum ultraviolet radiation $[2$, $25,26,29]$. 


\section{SLA material studies}

Due to trade secrets not much is known about the exact chemical composition of photopolymers. The main proprietary names are Sosmos $^{\circledR}$, Watershed ${ }^{\mathrm{tm}}$, Accura ${ }^{\circledR}$, Renshape $^{\mathrm{TM}}$ and Visijet ${ }^{\circledR}$ Flex SL. Typically, these are acrylic or epoxy photopolymers; however, unsaturated polyesters or urethanes or hybrid systems consisting of a combination of the two, can be used [41]. Somos ${ }^{\circledR} 7110$ and Renshape ${ }^{\mathrm{TM}} 5260$ were identified to contain epoxy and acrylic functional groups, aromatics and aliphatic ether groups [42], Flex SL was identified as a polyether (meth)acrylate-based resin [43], and Accura ${ }^{\circledR}$ SI40 is an epoxy photopolymer resin specifically designed for rapid manufacturing rather than prototyping, with properties considered to be closer to traditional engineering plastics [44].

A study of the impact of short term ageing (24 days) on the mechanical properties of Accura ${ }^{\circledR}$ SI 40 resin was done by Mansour et al. [44]. Samples were produced with a 3D Systems Inc. SLA 7000 machine (frequencytripled solid state laser, $354.7 \mathrm{~nm}$ ) according to dimensions specified by ISO standards for tensile, flexural and impact analysis [45-47]. The authors acknowledged the possible effect of build orientation on mechanical properties; however, to maximise the number of samples obtained from a same build, upright orientation ( $z$-axis) was adopted. All samples were produced, cleaned and UV post-cured at the same time after which they were kept in a dark controlled environment at $50 \% \mathrm{RH}, 20^{\circ} \mathrm{C}$. Every 4-5 days mechanical testing was performed and differential scanning calorimetry (DSC) carried out to quantify the extent of curing within samples. A relationship between mechanical properties and degree of cure was established. Tensile properties improved, yet impact strength and elongation at break were reduced, indicating that during the experiment, the material became stiff and more brittle. This confirmed that even after postcuring with UV radiation, SLA products are only partially cured [44].

Anisotropic properties of SLA objects were reported in a study assessing the effects of building orientation on mechanical properties [48]. Using the 3D system Viper si2 SL (with a solid state laser, $354.7 \mathrm{~nm}$ ) samples were fabricated according to dimensions for ASTM Type I [49] with a photopolymer resin, Watershed ${ }^{\mathrm{tm}} 11120$. Samples were fabricated in different orientations: flat, on edge (horizontally), and upright (vertically) within the build chamber. In addition, samples were laid out in different orientations on the building platform (along the $x$-axis, $y$-axis and diagonally). Samples were post cured in a UV oven for $30 \mathrm{~min}$. The direction of layer-to-layer interfaces was found to have a direct impact on mechanical properties and samples built horizontally had lower tensile strength than specimens built on edge or vertically, which had the highest tensile strengths. This indicates a high degree of anisotropy. The effect of ageing in three different environments: ambient, desiccated and desiccated but after 48 - $\mathrm{h}$ pre-conditioning in an environmental chamber at $23 \pm 2{ }^{\circ} \mathrm{C}$ and $50 \pm 5 \% \mathrm{RH}$ was studied over periods of 4, 30 and 120 days. A decrease in mechanical properties was observed in pre-conditioned samples due to the influence of humidity. The ultimate stress values increased over a period of 30 days, following which a decrease was noticed, indicating the onset of degradation following a short initial period of curing [48].

Tröger et al. [43] studied the degradation of two biocompatible acrylate-based resins (Flex SL ${ }^{\circledR} \mathrm{SE} / \mathrm{SM}-1500$ and Flex SL ${ }^{\circledR}$ SE/SM-25) used mainly for medical applications. Samples were prepared with a 3D Systems Viper si2 SL machine according to dimensions for tensile bars type S3A [50] and a specialised 3mat-Xtree test model was designed for thermal and humidity ageing tests [51, 52]. Samples were cleaned in an ultrasonic bath of isopropanol (1-2 $\mathrm{min}$ ) and UV post-cured for $20 \mathrm{~min}$ for Flex SL ${ }^{\circledR}$ SE/SM-1500 and 45 min for Flex SL ${ }^{\circledR}$ SE/SM- 25 . Four sets of experiments were conducted to investigate photodegradation (43 days in a greenhouse at 40-60\% $\mathrm{RH}$ and $20-33{ }^{\circ} \mathrm{C}, 0-93.6$ klux-average 14 klux, UV radiation dose $1.2-0.1 \mathrm{~mW})$, thermal degradation in a climate chamber $\left(70{ }^{\circ} \mathrm{C}\right.$ for 7 days) and degradation in high humidity (two experiments conducted in climate chambers at $50{ }^{\circ} \mathrm{C}, 85 \% \mathrm{RH}$ and $\left.70{ }^{\circ} \mathrm{C}, 100 \% \mathrm{RH}\right)$. Significant colour change was visually observed in all degraded samples and assigned to chemical decomposition of additives and thermo-oxidation of the polymer matrix resulting in by-products initiating further photo-oxidative reactions: auto-oxidation. An increase in mass from moisture absorption in high- $\mathrm{RH}$ conditions was observed in conjunction with a decrease in mechanical properties. The extreme greenhouse conditions and exposure to UV radiation accelerated degradation and all samples became harder. The changes were difficult to characterize exactly as the behaviour was not seen as typical for classical polymers.

Two studies by Salmoria et al. [42, 53] using FTIR, NMR and thermogravimetry investigated the curing kinetics and thermal degradation of liquid and cured Sosmos $^{\circledR} 7110$ and Renshape ${ }^{\mathrm{TM}} 5260$ resins. Samples of $4.50 \mathrm{~mm}$ diameter and $0.45-\mathrm{mm}$ height were produced using a SLA-250/30 machine from 3D-Systems Inc. with a HE-Cd laser $(325 \mathrm{~nm})$. Post curing was carried in a light chamber with 8 fluorescent lamps Phillips TLK $40 \mathrm{~W} / 05$ with a radiation range of $300-360 \mathrm{~nm}$. Thermal post-curing was also conducted with a Micro Quimica MQBEP 2000MP furnace in the Sosmos ${ }^{\circledR} 7110$ study [42]. Thermal curing was done at 124 and $149^{\circ} \mathrm{C}$. It was found that 
FTIR could be used to follow the cure conversion of the resin by monitoring the peak assigned to $\mathrm{C}=\mathrm{C}$ stretching vibration of acrylic groups $\left(1634 \mathrm{~cm}^{-1}\right)$ or epoxy groups $\left(2990 \mathrm{~cm}^{-1)}\right.$ which decrease due to chemical cross-linking as curing proceeds. In the Sosmos ${ }^{\circledR} 7110$ study [42], both thermal and photo curing conditions showed first order kinetics but the complete conversion of acrylic groups did not occur in any conditions studied. The curing process was accomplished and similar kinetic constant values for a thermal cure at $423 \mathrm{~K}\left(3.49 \times 10^{-2} \mathrm{~min}^{-1}\right)$ and the ultraviolet cure $\left(3.66 \times 10^{-2} \mathrm{~min}^{-1}\right)$ suggests that curing occurs through a similar mechanism under these conditions. In the Renshape ${ }^{\mathrm{TM}}$ study [53] it was found that the acrylate monomers $\left(6.8 \times 10^{-2} \mathrm{~min}^{-1}\right)$ reacts 3.7 times faster than the epoxy monomer $\left(1.8 \times 10^{-2} \mathrm{~min}^{-1}\right)$.

Despite SLA's reputation of producing dimensionally accurate parts, shrinkage has been reported after thermal degradation of thermoset photopolymers. Knowing the dimensional accuracy of printing is essential in order to be able to interpret change when studying dimensional change as a consequence of degradation of these materials [42, 54].

\section{Polyjet $^{\text {tm }}$}

Objet Geometries Ltd. was founded in 1998 and produces the line of PolyJet-based systems, marketed under the name Eden ${ }^{\mathrm{tm}}$. As SLA it involves the curing of a liquid photopolymer, however it differs in that it is not vat photopolymerisation by laser but is based on inkjet technology. The PolyJet ${ }^{\mathrm{tm}}$ system contains two cartridges supplying the part and support material. Materials are deposited by two jetting heads onto the building platform on the $x$ and $y$-axes. At the same time, a UV source (lamp) integrated into the jetting head cures the material. Parts are built in layers and once completed the non-toxic support material can be washed away with water, which is an advantage as no non-aqueous solvents are required (Fig. 4). A disadvantage is that the support material cannot be reused [30].

Polyjet $^{\mathrm{tm}}$ has designed their own system of photopolymer 'digital materials' whereby the printer prints combinations of two or three Polyjet ${ }^{\mathrm{tm}}$ base photopolymers to obtain a wide range of material properties simulating from elastomers and rubbers to production-grade ABS. Materials come in a range of colours and under the tradenames Vero (opaque rigid or clear) Tango, Durus and Rigus. Due to the shape recovery effect of polymers used for Polyjet, this 3D inkjet technology has led to the emergence of the innovative concept of 4D Printing with smart materials which react (change) to external stimuli, with time thus becoming the fourth dimension $[55,56]$. It is not yet known whether this technology has been adopted by artists, for mainstream design or even in heritage science, but it could pose significant conservation challenges in the future [56].

\section{PolyJet ${ }^{\mathrm{tm}}$ material studies}

A single study of a Polyjet ${ }^{\mathrm{tm}}$ material relevant to this review was published so far. The influence of time on the mechanical properties of ObjetVeroblue840 resin was investigated by Costa et al. [57]. Tensile testing [49] was conducted over a period of 120 days and cantilever tests were conducted over a period of 90 days on samples of dimensions $60 \times 20 \times 4 \mathrm{~mm}$. All samples were produced in a longitudinal direction with a layer deposition thickness of $16 \mu \mathrm{m}$ on an Objet Eden $350 \mathrm{~V}$ machine which uses a UV lamp to cure the liquid photopolymer as it is deposited. There was a reduction of both properties studied over time, particularly in the first 30 days after which values stabilized [57]. These results could be due to parts having not been fully cured after prototyping, as is the case with SLA. More research is needed into the extent of cure of Polyjet parts, the effects of different environmental conditions on degradation and building orientations on anisotropy.

\section{Powder based systems \\ Selective laser sintering (SLS)}

Selective Laser Sintering (SLS) works by a $\mathrm{CO}_{2}(10.6 \mu \mathrm{m})$ or Nd: YAG $(1.06 \mu \mathrm{m})$ laser selectively sintering the contours of a cross section corresponding to the CAD model onto a thin layer of powder spread on the building platform. The laser sinters particles by heating them just enough for their surfaces to soften (melt) and fuse at the point of contact (unlike complete melting where the molten flow of the material can cause deformation). The powder in the build chamber is heated and kept to a temperature just below the glass transition temperature, to reduce thermal distortion and to aid fusion between layers. Un-sintered powder remains in place as support $[26,58]$. The processes of sintering have been theoretically and computationally modelled based on current understanding of laser-matter interaction, and reviewed [59].

In theory any thermoplastic material ground into a powdered form should be suitable for laser sintering but practically this is not the case. A range of factors can prevent production of good quality prototypes such as: different thermal properties of different materials, availability of powdered polymers with suitable particle size and morphology, broad thermal processing window and limitations in laser sintering systems. This has been discussed elsewhere [58]. The density and porosity of the sintered part will depend on the size of the particles and how densely these are packed in the build chamber. Other SLS parameters such as laser wavelength, laser energy, temperature distribution within the build chamber can also affect the mechanical properties of the part such as porosity or anisotropy [58]. 
The two main providers of SLS system are 3D Systems Ltd and EOS GmbH Electro Optical Systems (Krailling) [60]. SLS systems differ mainly in the way powder is deposited, either by a roller from feed chambers or by a sieving action. The typical materials in use are polycarbonate (PC), acrylonitrile butadiene styrene (ABS), nylon (PA 12), polyester (PET), polypropane (PP), polyurethane (PU), poly(lactic acid (PLA) and wax.

Despite continuing developments to increase the range of materials polyamide (PA) 12 is still the most commonly used SLS material (constituting 95 \% of all prototypes) as it is easy to process and inexpensive [58] (Fig. 5).

A distinction can be made between amorphous and semi-crystalline thermoplastics used in SLS. Limited success has been achieved with amorphous polymers such as $\mathrm{PC}$ which do not have a clear melting temperature range but have a glass transition temperature at $\sim 100{ }^{\circ} \mathrm{C}$ above which the polymer gradually softens becoming rubbery and as temperature increases finally becomes a liquid, without clear transitions. They have a flow and sintering rate less than that of semi-crystalline polymers (such as PA 12) and so are more porous, weaker and less durable. They do however produce more dimensionally accurate parts with good resolution. Semi-crystalline polymers such as PA 12, which have sharp melting points and quickly become viscous liquids, can be sintered to make very dense prototypes with properties comparable to injection-moulded materials. However, they exhibit greater shrinkage (3-4\%) resulting in less accurate parts [28].

\section{Selective laser sintering (SLS) material studies}

Building parameters such as laser power, scanning speed, layer thickness, powder bed temperature, building positions and orientation of parts all contribute to the material characteristics of laser-sintered polymers [58]. The most commonly used material for laser sintering is DuraForm ${ }^{\circledR} \mathrm{GF}$, a glass-filled polyamide 12 by 3D Systems Ltd.

It has been shown that higher energy delivery by laser radiation or increase in powder bed temperatures increase part density, reduce anisotropy, and yield higher tensile strength values, Young's modulus and elongation at break. This window is limited as at very high energy densities the properties level-off or begin to decrease [61].

An investigation into the effect of processing parameters on PA 12, using ASTM type 1 [49] samples built with a Sinterstation 25000 plus from 3D Systems Ltd. was conducted by Starr et al. [62]. The laser power varied from 7 to $20 \mathrm{~W}$ and the bed temperature was kept at $166^{\circ} \mathrm{C}$. The scan speed ranged from 2.540 to $5.080 \mathrm{~mm} \mathrm{~s}^{-1}$, and scan spacing from 0.10 to $0.20 \mathrm{~mm}$ with layer thickness from
0.10 to $0.15 \mathrm{~mm}$. Samples were built in six orientations to investigate the influence of build orientation. The maximum yield and ultimate tensile strength value recorded for laser sintered DuraForm $12^{\circledR}$ were found to be similar to injection-moulded PA 12. These values were achieved for all orientations at the highest laser power. At lower power differences in yield stress were observed, particularly for samples built in the $\mathrm{z}$ orientation, i.e. vertically [62].

To save on costs and minimize material consumption, 80-95\% of un-sintered powder left in the build chamber after printing is recycled and a blend of virgin and reused powder are often used. Due to processing conditions such as heating and cooling of the building chamber, un-sintered powder degrades, causing a gradual reduction in quality. Temperature in the bed chamber and duration of the sintering process have major influences on the rate of this process. This also varies according to the location within the build chamber, and it was found that PA 12 powder (PA2200, EOS GmbH) collected and analysed towards the centre and the base of the build chamber had a lower melt flow rate and are therefore less usable [60]. The powder was collected from two SLS machines EOSINT P700 (EOS GmbH) and Sinterstation $^{\text {tm }} 2500$ HIQ (3D Systems Ltd). The term "orange peel" has been used to describe the phenomenon which occurs after too many repeated cycles without refreshing with virgin powder where a rough surface resembling the skin of a peeled orange arises [60].

Cooke et al. [63] found that in the majority of studies into the anisotropy of SLS objects not all building orientations were included and sample numbers were insufficient to provide statistically significant results. Using 288 DuraForm ${ }^{\circledR}$ GF samples produced using a Sinterstation HIQ (3D Sytems Ltd.) they investigated three different building orientations and the effect of "ageing" (defined as moisture absorption) of samples stored in a nondesiccated environment for 43 days. The samples were found to be transversely isotropic (i.e. isotropic within a layer) as the position of samples within the build chamber greatly affected densification, which could be a result of temperature distribution. Sensitivity of material properties to slight changes in building parameters was also noted [64].

In contradiction to these findings, Majewski and Hopkinson found that section thickness and build orientations had no significant impact on PA 12 (PA2200, EOS $\mathrm{GmbH}$ ) laser sintered parts produced on the EOS Formiga P100 machine in their study. However, a decrease in molecular weight between samples produced early in the build and ones produced later was noted, which could be a result of longer exposure to higher temperatures [63]. 


\section{D printing ${ }^{\mathrm{TM}}$}

Z-Corporation's 3DP ${ }^{\mathrm{TM}}$ process is the fastest RP technology available, and at half the cost of other systems has become very popular (Fig. 6). It was estimated in 2006 to be the third-best seller in RP machines [25].

3DP is based on ink-jet technology. A thin layer of powdered material is spread on a building piston by a roller from the powder feed piston. Ink-jetting a binder solution onto the powder selectively joins the powdered material. The loose powder around the part stays in place to act as support. Once a cross-section is completed the build piston is lowered and the powder feed piston is raised to allow for another layer of powder to be rolled over ready for the next layer to be bonded [24, 25]. The object is then infiltrated for strength with an epoxy, cyanoacrylate or phenolic resin [30].

3DP is very versatile as without changing the primary binding material an array of material properties can be achieved by using different powdered materials and adding infiltrants. Z Corporation is the leading provider of 3DP technology. They have developed a composite in powder form, which can be post-cured by spraying with water making it the safest and 'greenest' post-curing option. Their machines are also capable of automatically removing and recycling loose powder [30].

There is also a $3 \mathrm{DP}^{\mathrm{TM}}$ colour system available where the binder fluid is coloured [65]. This has made 3DP popular amongst architects, artists and within the cultural heritage sector, for printing coloured models and replicas [24]. The ZPrinter ${ }^{\circledR} 450$ uses a single tri-colour print head, which is quick to change, and costs less than systems with multiple print heads [30].

\section{$3 D$ printing ${ }^{\mathrm{TM}}$ material studies}

While the more established processes of SLS and SLA received more attention, factors such as low cost and speed make ZCorporation 3D Printing increasingly popular. Until recently it was mainly used for concept modelling rather than for manufacture of end-use products. In 2000 the first commercial colour rapid manufacturing system was launched, the Z402C colour printer [66]. What sets 3D colour printing apart from other RP colour technologies (Laminate Object Manufacturing ${ }^{\mathrm{TM}}$ (LOM) and SLS), is that the coloured ink is also the binder. $3 \mathrm{DP}^{\mathrm{TM}}$ provides high-resolution (up to $600 \times 540 \mathrm{dpi}$ ) colour prints [67]. However the bonds between particles are not as strong as LOM or SLS manufactured parts where materials are heated to a molten state for bonding and strength of 3DP parts are mainly dependant on infiltration method [66].

The exact composition of materials are trade secrets, however some information is available [67-70]. The $\mathrm{zp}^{\mathrm{TM}} 130$ powder consists of a plaster containing crystalline silica (50-90\%), a vinyl polymer (2-20\%) and sulfate salt $(0-5 \%)$. The binder $\mathrm{zb}^{\mathrm{TM}} 58$ contains glycerol (1-10\%), sorbic acid salt (0-2\%), an unknown surfactant $(<1 \%)$, pigment $(<20 \%)$ and water $(85-95 \%)$. There are various options for the infiltrant: the most popular are cyanoacrylate, epoxy or wax. Z Corporation has also developed a water-cure system using their composite powder, $\mathrm{zp}^{\mathrm{TM}} 150$, which consisting of plaster, a vinyl polymer and carbohydrate (starch). The parts are cured by spraying water and $\mathrm{MgSO}_{4}$ (epsom salt). Rubber-like properties can be achieved with their zp15e powder mixture of cellulose, 'specialty fibers', and additives which are capable of absorbing a urethane elastomer, such as PorA-Mold [30, 68].

Very little research has been conducted into the material properties (thermal, strength or fatigue) of $3 \mathrm{DP}^{\mathrm{TM}}$ parts and there is a need for research into material degradation and behaviour at different environmental conditions [65], especially taking into account the growing popularity of this system.

Cyanoacrylate is a popular infiltrant due to ease of use and rapid curing by anionic mechanisms which is initiated in the presence of a weak base such as adsorbed moisture on the surface of substrates. This reaction continues until terminated with an acid. The depth of infiltration can be reduced if the model is not fully dried as reactions take place closer to the surface, block pores and prevent penetration of the infiltrant into the bulk of the material [71].

In a degradation study of an epoxy infiltrated 3DP ${ }^{\mathrm{TM}}$ artworks by Karen Sander, the infiltrant was identified as an aliphatic epoxy resin. Accelerated degradation of reference samples prepared identically to the artwork, using a commercial epoxy (LB Klar, epoxy pre-polymer mix with polyamine hardener) was carried out, and analysis revealed progressive formation of amides. Yellowing was attributed to the formation of quinoid chromophores [72].

The colour properties and permanence of customised 3D printed colour samples produced on a ZCorp Z510 printer with Zp131 plaster-based powder and Zb60 Cyan, Magenta and Yellow binders were studied by Stanic et al. [24]. Three sets of samples were prepared: untreated, treated with a cyanoacrylate infiltrant (Belinka Kemostik, Slovenia) and treated with a two-part epoxy infiltrant (Selemix 7-410 and Selemix 9-011, Iridia, Italy/ PPG Industries, UK). Colourimetry was used after photodegradation in a Xenotest Alpha chamber for $72 \mathrm{~h}$ in accordance to lightfastness testing standards [73-75] at $42 \mathrm{~W} \mathrm{~m}{ }^{-2}, 300-400 \mathrm{~nm}, 35^{\circ} \mathrm{C}$, black standard temperature $50{ }^{\circ} \mathrm{C}, 35 \% \mathrm{RH}$.

Infiltrants not only contribute to mechanical properties but also enhance colour saturation. Cyanoacrylate infiltration contributed to higher chroma and lightness 
values. The colour stability varied and was found to depend on the binder colour, infiltrant used and the percentage of ink coverage. In both infiltrated and uninfiltrated samples the magenta colour patches showed the biggest total colour change, and in the uninfiltrated samples these were followed by yellow and then cyan. The reverse was observed for infiltrated samples with cyan exhibiting more colour change than yellow. All samples irrespective of the infiltrant became less saturated and faded. All uncoloured samples, infiltrated and non-infiltrated, yellowed during accelerated degradation, but the change was most pronounced in epoxy infiltrated samples [24].

\section{Materials extrusion}

\section{Fused deposition modelling (FDM $\left.{ }^{\circledR}\right)$}

Fused deposition modelling works on the principle of phase change of a thermoplastic material (Fig. 7). A thermoplastic filament $(0.178 \mathrm{~cm}$ in diameter $)$ is heated to a semi-molten state and extruded by a nozzle moving around on the $x-y$ plane depositing traces on the working platform. The model is built up in layers according to cross-sectional data. Lowering the platform in the $z$ direction to a specified distance allows for deposition of subsequent layers. The molten material fuses with the layer underneath. A second nozzle extrudes support material where required. The traces can be set to follow specified raster orientations and can be alternated between layers. This layering in different orientations gives $\mathrm{FDM}^{\circledR}$ parts anisotropic properties [76].

The most commonly used materials are poly(lactic acid) (PLA), polyphenylsulfone (PPS), Polycarbonate $(\mathrm{PC})$, acrylonitrile butadiene styrene (ABS) and ABScontaining materials, e.g. PC-ABS blend and are sold under trademarks ABSi $^{\text {TM }}$, PC-ISO, ASA ULTEM 1010 resin.

\section{Fused deposition modelling $\left(F D M^{\circledR}\right)$ material studies}

One of the most frequently used thermoplastic polymers in $\mathrm{FDM}^{\circledR}$ processes is ABS. It can be used across all of Stratasys FDM ${ }^{\circledR}$ machines [25]. ABS is a two-phase material consisting of rubbery polybutadiene embedded in a matrix of styrene which has been co-polymerised with acrylonitrile, which gives the final material its unique characteristics such as impact, heat and chemical resistance $[25,77]$.

It is known that ABS has poor resistance to photo-oxidation due to the unsaturated elastomer polybutidine [38, $78,79]$. ABS also has poor resistance to cyclic fatigue [77].

Research was undertaken into the anisotropic properties of $\mathrm{FDM}^{\circledR}$ objects using ABS built on a Stratasys FDM 1650 machine with ABS P400 filament material. Raster orientation, air gap, bead width, colour and model temperature were explored and tensile and compressive tests were carried out and compared to injectionmoulded samples using ABS P400. Air gaps between traces and raster orientation were found to significantly affect tensile strength while other parameters had little impact [76].

The effect of three processing parameters (fill density, horizontal and vertical direction) on dimensional stability and strength of FDM produced parts in ABS was discussed by Guralla and Regalla. The effects were found to be conflicting, with a choice having to be made between optimum dimensional stability and strength as different processing parameters were required [80].

PLA is a co-polymer of lactic and glycolic acids and is fully biodegradable when composted at temperatures above its $T_{g}$ of $60{ }^{\circ} \mathrm{C}$. PLA is susceptible to hydrolytic degradation, the rate of which depends on factors such as molecular structure, $T$ and $\mathrm{pH}$ [81]. Hydrolysis is accompanied by oxidative degradation and trans-esterification reactions [82-84]. It is likely that PLA will represent a significant conservation issue due to its instability.

\section{Conclusions}

Rapid prototyping has excited artists and designers, and objects are becoming part of museum collections. Additionally, heritage institutions use rapid prototyping to engage with the public in new ways, and conservators use it to produce replacement parts. Heritage scientists and conservators are uniquely positioned to engage with artists to collect details on materials and technologies used, as well as acquire information on the early technologies before these become obsolete.

Artists and designers seem to prioritise conservation of the physical print over the digital file indicating a sense of the ephemeral nature of the digital copy. This also highlights the immense challenge of digital preservation as well as the importance of preserving the physical artwork. Through this literature review it became clear that there are significant gaps in rapid prototyping materials characterisation and conservation research.

Of the materials currently used in RP, which include ceramics, metals and polymers, the latter are probably going to represent the biggest challenge to conservation. Therefore, literature was reviewed by specifically focusing on five technologies in which polymers are used as base materials: stereolithography, fused deposition modelling, 3D Printing, selective laser sintering and polyjet.

So far, most research focused on mechanical properties of RP materials and products. The main concerns were tensile strength, impact resistance and the effect of short-term curing and ageing on these properties. The effects of building parameters have been explored for most technologies and anisotropy was highlighted in 
several studies. This could represent an important issue in conservation as it could lead to deformation in the long-term. However, more research needs to be done to understand what role anisotropy could play in the degradation of RP products.

A limited number of studies dealt with degradation in the long term of RP, one related to Stereolithography and one to the colour stability of 3D prints. The results indicate the instability of base polymers as well as of additives such as dyes. There is a significant gap in the literature regarding the nature of dyes and pigments used in RP technologies and how these affect the photochemical stability of RP products. Before use in conservation applications further research is required into RP material properties, specifically to identify potential risks associated with direct contact between replacement parts and historic material as differences in expansion/contraction properties or the release of plasticisers or other RP components could be damaging to the original artefact. Another consideration is the risk related to repeated conservation treatments if objects have to be re-visited to remove degraded/discoloured replacement parts.

The range of RP processes and materials is continuously developing and changing. Due to demand for low carbon manufacturing, systems might become commonplace that are particularly 'green'. However, very little research has been done regarding recyclability of RP materials and the effect of this on long-term stability of the end-product. Poly(lactic) acid has gained popularity in $\mathrm{FDM}^{\circledR}$ and SLS ${ }^{\circledR}$ due to its biodegradability which is beneficial in terms of its environmental impact, but this will potentially lead to even more complex conservation problems.

Despite their seemingly ephemeral nature, rapid prototypes need to be considered as a conservation challenge. Given that many objects are individually treated by artists in post-production, non-destructive or micro-destructive research methods may need to be developed and applied such that they can be used on the objects themselves, e.g. microfadeometry for studies of colour stability or microindentation methods for studies of mechanical properties. Heritage science should not only observe the manufacturing revolution, it needs to actively inform the developments so as to prevent conservation nightmares in the future.

\section{Additional files}

Additional file 1. Additional data.

Additional file 2. The digital artwork for "Out of the Cauldron" by Tom Lomax, available to download.

Additional file 3. Digital artwork "Out of the Cauldron" by the Artist Tom Lomax. Available to download for printing in .stl format.

Additional file 4. Digital artwork "Out of the Cauldron" by the Artist Tom Lomax. Available to download for printing in .ply format.

\section{Authors' contributions}

CC and MS jointly developed the concept of this review. CC, BP and MS developed the survey and CC analysed the data. TL designed the objects used in the engagement experiment, and $\mathrm{BP}$ developed the degradation experiment. All co-authors contributed to the manuscript. All authors read and approved the final manuscript.

\section{Author details}

${ }^{1}$ Institute for Sustainable Heritage, University College London, London, UK.

${ }^{2}$ Victoria and Albert Museum, London, UK. ${ }^{3}$ Sculptor, London, UK.

\section{Acknowledgements}

The Design with Heritage Knowledge Exchange Project was funded by the UK Arts and Humanities Research Council. We are very grateful to Onya McCausland, Emily Pavlatou and Sarah Younan for the collaborative work that led to the demonstration of discolouration of prototypes, and for collaboration on the survey of artist and designers' practices. We thank all participants in the interviews and surveys, in particular to Mat Chivers, Geoff Mann, Luc Merx, Keith Brown, and Bathsheba Grossman for their comments and again to Geoff Mann, Nick Ervinck, Sophie Kahn and WertelOberfell for having allowed us to reproduce the photographs of designs and artworks.

We are further grateful to the EPSRC Centre for Doctoral Training Science and Engineering in Arts, Heritage and Archaeology (SEAHA) and to EU Horizon 2020 project Nanorestart, for funding. We are further grateful to Yvonne Shashoua (National Museum of Denmark) for valuable discussions.

\section{Competing interests}

The authors declare that they have no competing interests.

Received: 31 March 2016 Accepted: 8 July 2016

Published online: 22 November 2016

\section{References}

1. Benjamin W. The work of art in the age of mechanical reproduction, translated by Underwood JA, editor. London: Penguin Group; 2008.

2. Bechtold T. Rapid prototyping in museum collections. Technologyapplications_durability. In: Bechtold T, editor. Future talks 011 technology and conservation of modern materials in design. Munich: Die Neue Sammlung, The International Design Museum; 2011. p. 47-55.

3. BS ISO/ASTM 52900:2015. Additive manufacturing-general principlesterminology. London: BSI Standards Limited; 2016.

4. Minder R. At Museo del Prado, blind visitors can touch masterpieces. The New York Times. 2015. http://www.nytimes.com/2015/03/07/arts/ design/at-museo-del-prado-blind-visitors-can-touch-masterpieces.html. Accessed 2 Apr 2015.

5. Neumüller M, Reichinger A, Rist F, Kern C. 3D printing for cultural heritage: preservation, accessibility, research and education. In: Ioannides M, Quak $\mathrm{E}$, editors. 3D research challenges in cultural heritage: a roadmao in digital heritage preservation. Heidelberg: Springer; 2014. p. 119-34. http://link. springer.com/chapter/10.1007/978-3-662-44630-09. Accessed 2 Apr 2015

6. Sloan R. Dancing the flip-flop. 2014. http://www.robinsloan.com/note/ flip-flop/2014. Accessed 3 Apr 2015.

7. Neely $\mathrm{N}$, Langer M. Please feel the museum: the emergence of $3 \mathrm{~d}$ printing and scanning. MW2013: museums and the web. 2013. http:// mw2013.museumsandtheweb.com/paper/please-feel-the-museum-theemergence-of-3d-printing-and-scanning/. Accessed 3 Apr 2015.

8. McDevitt N. Facial reconstructions bring redpath mummies to life. 2014 http://publications.mcgill.ca/reporter/2014/01/facial-reconstructionsbring-redpath-mummies-to-life/2014. Accessed 6 Jan 2016.

9. Schultz, C. A bust of Richard III, 3D-printed from a scan of his recently exhumed skull. 2013. http://www.smithsonianmag.com/smart-news/abust-of-richard-iii-3d-printed-from-a-scan-of-his-recently-exhumedskull-65419134/. Accessed 6 Jan 2016.

10. Nicolas T, Gaugne R, Tavernier C, Gouranton V, Arnaldi B. Preservative approach to study encased archaeological artefacts. In: loannides M, Quak E, editors. 3D research challenges in cultural heritage: a roadmap 
in digital heritage preservation. Heidelberg: Springer; 2014. p. 332-41. doi:10.1007/978-3-319-13695-0_32.

11. Fantini M, de Crescenzio F, Persiani F, Benazzi S, Gruppioni G. 3D restitution, restoration and prototyping of a medieval damaged skull. Rapid Prototyp J. 2008;14(5):318-24. doi:10.1108/13552540810907992.

12. Soe SP, Eyers DR, Jones T, Nayling N. Additive manufacturing for archaeological reconstruction of a medieval ship. Rapid Prototyp J. 2012;18(6):443-50. doi:10.1108/13552541211271983.

13. Allen Z, James P. The conservation of marie antoinette's chair. 2015. http://www.vam.ac.uk/blog/conservation-blog/the-conservation-ofmarie-antoinettes-chair. Accessed 3 Apr 2015.

14. Frood E, Parkinson R, Lowe A. Conserving by copying: 3D printing Tutankhamun's tomb. http://partnership.ox.ac.uk/conserving-by-copying3d-printing-tutankhamuns-tomb/\#.VR6kXd6Gqzc. Accessed 3 Apr 2015

15. Kingsley P. Exact replica of Tuthankhamen's tomb unveiled in Egypt. The Guardian. 2014. http://www.theguardian.com/world/2014/may/01/ exact-replica-tutankhamun-tomb-egypt. Accessed 14 Mar 2016.

16. Karp C. Digital heritage in digital museums. Mus Int. 2004;56(1-2):45-51. doi:10.1111/j.1350-0775.2004.00457.

17. Madden O, Learner T. Preserving plastics: an evolving material, a maturing proffession. Conservation perspectives: The GCI Newsletter. Conservation of plastics. Spring 2014. p. 4-9. http://www.getty.edu/conservation/publications_resources/newsletters/pdf/v29n1.pdf. Accessed 29 Dec 2015.

18. Albus SB et al. Plastic art-a precarious success story. Cologne: AXA Art Versicherung. 2007. http://broker-it.axa-art.info/fileadmin/Cluster/IT/ PRODUKTE/Additional_Material/Plastic_Art.pdf. Accessed 14 Mar 2016.

19. Drizo A, Pegna J. Environmental impacts of rapid prototyping: an overview of research to date. Rapid Prototyp J. 2006;12(2):64-71. doi:10.1108/13552540610652393.

20. Lavédrine B, Fournier A, Martin G, editors. The preservation of plastic artefacts in museum collections. Paris: CTHS; 2012.

21. Shashoua Y. Conservation of plastics: materials science, degradation and preservation. Oxford: Butterworth-Heineman, Elsevier; 2008.

22. OBJET RGD515. MSDS ID: DOC-06108_C [Online] Stratasys GmbH: Rheinmünster, Germany, January 22, 2013. http://www.stratasys.co.jp/materials/material-safety-data-sheets/polyjet/ /media/6125876D931544A3918 C3CA23E8220E1.pdf. Accessed 15 Feb 2016.

23. Madsac D. Rapid prototyping-rapid ageing? Technology and ageing properties of contemporary art and design objects made by rapid prototyping technologies. In: Bechtold T, editor. Future talks 011 technology and conservation of modern materials in design. Munich: Die Neue Sammlung, The International Museum; 2011. p. 57-65.

24. Stanic M, Lozo B, Svetec DG. Colorimetric design properties and stability of 3D prints. Rapid Prototyp J. 2012;18(2):120-8.

25. Noorani R. Rapid prototyping: principles and applications. New Jersey: Wiley; 2006

26. Pham DT, Gault RS. A comparison of rapid prototyping technologies. Int J Mach Tools Manuf. 1998;38:1257-8.

27. Chua CK, Leong KF. 3D printing and additive manufacturing: principles and applications. 4th ed. Singapore: World Scientific; 2014.

28. Levy GN, Schnidel R, Kruth JP. Rapid manufacturing and rapid tooling with layer manufacturing (LM) technologies, state of the art and future perspectives. CIRP Ann ManufTechnol. 2003;52(2):589-609.

29. Yan X, Gu P. A review of rapid prototyping technologies and systems. Comput Aided Des. 1996;28(4):307-18.

30. Chua CK, Leong KF, Lim CS. Rapid prototyping: principles and applications. 3rd ed. Singapore: World Scientific Publishing Co., Pte. Ltd; 2010.

31. Wohlers T, Caffrey T. Wohlers report 2015. Colorado:Wohlers Associates; 2015.

32. Wohler T, Gornet T. Viewpoint: history of additive fabrication (part 1). 2007. http://www.wohlersassociates.com/MarApr08TCT.htm. Accessed 30 Nov 2012.

33. ASTM Standard F2792-12a. Standard terminology for additive manufacturing technologies ASTM International, West Conshohocken. 2012.

34. Nguyen QT. Polymer degradation and stabilization. In: Meyer T, Keurentjes J, editors. Handbook of polymer reaction engineering. Weinheim: Wiley$\mathrm{VCH} ; 2005$.

35. Rychlý J, Strlič M. Degradation and ageing of polymers. In: Strlič M, Kolar J, editors. Ageing and stabilization of paper. Ljubljana: National and University Library; 2005. p. 9-23.
36. McNeill IC. Fundamental aspects of polymer degradation. In: Allen NS, Edge M, Horie MV, editors. Polymers in conservation. Cambridge: Royal Society of Chemistry; 1992. p. 14-31.

37. Celina MC. Review of polymer oxidation and its relationship with materials performance and lifetime prediction. Polym Degrad Stab. 2013;98(12):2419-29.

38. Grassie N, Scott G. Polymer degradation and stabilisation. Cambridge: Cambridge University Press; 1985. ISBN 0521249619.

39. Partanen J. Solid state lasers for stereolithography. In: 7th annual solid freeform fabrication symposium proceedings. 1996. p. 369-76. http:// sffsymposium.engr.utexas.edu/Manuscripts/1996/1996-45-Partanen.pdf. Accessed 6 Jan 2016.

40. Rauch T, Delmdahl R. Advanced UV lasers enable precision processing. Laser Tech J. 2009;6(3):20-4. doi:10.1002/latj.200990034.

41. Hanemann T, Bauer W, Knitter R, Woias P. Rapid prototyping and rapid tooling techniques for manufacturing of silicon, polymer, metal and ceramic microdevices. In: Leondes CT, editor. MEMS/NEMS: handbook techniques and applications. New York: Springer; 1992. p. 5.

42. Salmoria GV, Gonzalez VJ, Ahrens CH, Soldi V, Pires ATN. Stereolithography Somos 7110 photosensitive resin: study of curing kinetic and thermal degradation. J Mater Process Technol. 2005;168(1):164-71. http://linkinghub.elsevier.com/retrieve/. Accessed 9 Apr 2015.

43. Tröger C, Bens AT, Bermes G, Klemmer R, Lenz J, Irsen S. Ageing of acrylate based resins for stereolithography: thermal and humidity ageing behavior studies. Rapid Prototyp J. 2008;14(5):305-17. doi:10.1108/13552540810907983.

44. Mansour S, Gilbert M, Hague R. A study of the impact of short-term ageing on the mechanical properties of a stereolithography resin. Mater Sci Eng A. 2007:447(1-2):277-8. doi:10.1016/j.msea.2006.10.007.

45. ISO 527-1 and 2, Plastics-determination of tensile properties. 1996.

46. ISO 178, Plastics-determination of flexural properties. 1997.

47. ISO 180, Plastics_-determination of Izod impact strength. 2001.

48. Puebla K, Arcaute K, Quintana R, Wicker RB. Effects of environmental conditions, aging and build orientation on the mechanical properties of ASTM type I specimens manufactured via stereolithography. Rapid Prototyp J. 2012;18(5):374-88. doi:10.1108/13552541211250373.

49. ASTM Standard D638. 2005. Standard test method for tensile properties of plastics. ASTM International, West Conshohocken. 2012. doi:10.1520/ D0638-14.

50. DIN 53504:1994 Testing of rubber; determination of tensile strength at break, tensile stress at yield, elongation at break and stress values in a tensile test. Deutsches Institut Fur Normung E.V. (German National Standard).

51. DIN53508:2000 Testing of rubber-accelerated ageing. Deutsches Institut Fur Normung E.V. (German National Standard).

52. DIN EN ISO 2440:2000-01 Flexible and rigid cellular polymeric materials_-accelerated ageing tests. Deutsches Institut Fur Normung E.V. (German National Standard).

53. Salmoria GV, Klauss P, Pires ATN, Roeder J, Soldi V. Investigations on cure kinetics and thermal degradation of stereolithography Renshape ${ }^{\mathrm{TM}} 5260$ photosensitive resin. Polym Test. 2008;27(6):698-704. http://linkinghub. elsevier.com/retrieve/. Accessed 12 Jan 2016.

54. Berger $U$. Aspects of accuracy and precision in the additive manufacturing of plastic gears. Virtual Phys Prototyp. 2015;10(2):49-57.

55. Yap YL, Yeong WY. Shape recovery effect of 3D printed polymeric honeycomb: This paper studies the elastic behaviour of different honeycomb structures produced by PolyJet technology. Virtual Phys Prototyp. 2015;10(2):91-9.

56. Khoo ZX, Teoh JEM, Liu Y, Chua CK, Yang S, An J, Yeong WY. 3D printing of smart materials: a review on recent progresses in $4 \mathrm{D}$ printing. Virtual Phys Prototyp. 2015;10(3):103-22. doi:10.1080/17452759.2015.1097054.

57. Costa CA, Linzmaier PR, Pasquali F, Rezende R. Conference Paper: 6th IFAC Conference Management and Control of Production and Logistics. At Fortaleza. 2013; doi:10.3182/20130911-3-BR-3021.00118.

58. Goodridge RD, Tuck CJ, Hague RJM. Laser sintering of polyamides and other polymers. Prog Mater Sci. 2011;57:229-67. http://www.sciencedirect.com/science/article/.

59. Kruth JP. Rapid manufacturing and rapid tooling with layer manufacturing (LM) technologies, state of the art and future perspectives. CIRP Annal Manuf Technol. 2003;52(2):589-609. 
60. Dotchev K, YusoffW. Recycling of polyamide 12 based powders in the laser sintering process. Rapid Prototyp J. 2009;15(3):192-203. doi:10.1108/13552540910960299.

61. Blattmeier M, Witt G, Wortberg J, Eggert J, Toepker J. Influence of surface characteristics on fatigue behaviour of laser sintered plastics. Rapid Prototyp J. 2012;18(2):161-71. doi:10.1108/13552541211212140.

62. Starr TL, Gornet JT, Usher JS. The effect of process conditions on mechanical properties of laser-sintered nylon. Rapid Prototyp J. 2011;17(6):418-23. doi:10.1108/13552541111184143.

63. Cooke W, Tomlinson RA, Burguete R, Johns D, Vanard G. Anisotropy, homogeneity and aging in an SLS polymer. Rapid Prototyp J. 2011;17(4):269-79. doi:10.1108/13552541111138397.

64. Majeweski C, Hopkinson N. Effect of section thickness and build orientation on tensile properties and material characteristics of laser sintered nylon-12. Rapid Prototyp J. 2011;17(3):176-80. doi:10.1108/13552541111124743.

65. Dimitrov D, Schreve K, de Beer N. Advances in three-dimensional printing — state of the art and future perspectives. Rapid Prototyp J. 2006;12(3):136-47. doi:10.1108/13552540610670717.

66. Gibson I, Ming LW. Colour RP. Rapid Prototyp J. 2001;7(4):212-6. doi:10.1108/EUM0000000005894.

67. Z Corporation. The fastest most afforable color 3D printing. Brochure: 3DP-BRO-2010. Z Corporation, Burlington, USA. 2010.

68. Z Corporation. 3DP ${ }^{\mathrm{TM}}$ Consumer Catalog. Part Number 09572. 2009. http://www.bibus.sk/fileadmin/product_data/3D-Systems/documents/ zcorp_series_3dp_consumables_catalogue_en_f19_2009.pdf.

69. Z Corp. zp130 powder MSDS 8/04. 2005 http://ytec3d.com/wp-content/ uploads/2014/08/zp130.pdf. Accessed 14 Mar 2016.

70. Z Corp. Z Corp. zp150 powder MSDS 83013. 2009. https://www.shapeways.com/rrstatic/material_docs/msds-sandstone.pdf. Accessed 14 Mar 2016

71. Alam A, Bredt JF, Clark N, Flynn M, Sprauer J, Williams DX. Three-dimensional printing material system with improved color, article performance, and ease of use. Google Patents. 2009. http://www.google.com/patents/ EP2109528A1?cl=en. Accessed 14 Mar 2016.

72. Lazzari M, Ana Ledo-Suárez A, López T, Scalarone D, López-Quintela MA. Plastic matters: an analytical procedure to evaluate the degradability of contemporary works of art. Anal Bioanal Chem. 2011;399(9):2939-48. doi:10.1007/s00216-011-4664-5
73. ASTM. F2366-05 standard practice for determining the relative lightfastness of ink jet prints exposed to window filtered daylight using a xenon arc light apparatus. West Conshohocken: American Society for Testing and Materials International; 2005.

74. ASTM. D3424-09 standard practice for evaluating the relative lightfastness and weatherability of printed matter. West Conshohocken: American Society for Testing and Materials International; 2009.

75. ISO 11341:2004 Paints and varnishes-artificial weathering and exposure to artificial radiation-exposure to filtered xenon-arc radiation. 2004.

76. Ahn S, Montero M, Odell D, Roundy S, Wright PK. Anisotropic material properties of fused deposition modeling ABS. Rapid Prototyp J. 2002;8(4):248-57. doi:10.1108/13552540210441166.

77. Karahaliou E-K, Tarantili PA. Stability of ABS compounds subjected to repeated cycles of extrusion processing. Polym Eng Sci. 2015;49(11):2269-75. doi:10.1002/pen.21480.

78. Scheirs J. Compositional and failure analysis of polymers: a practical approach. Chichester: Wiley; 2000.

79. Adams ME, Buckley DJ, Colborn RE. Acrylonitrile-butadiene-styrene polymers. Rapra review reports, vol 6(10). Rapra Technology Ltd.; 1993;

80. Gurrala PK, Regalla SP. Multi-objective optimisation of strength and volumetric shrinkage of FDM parts: a multi-objective optimization scheme is used to optimize the strength and volumetric shrinkage of FDM parts considering different process parameters. Virtual Phys Prototyp. 2014;9(2):127-38

81. Tsuji H. Hydrolytic degradation. In: Auras R, editor. Poly(lactic acid): synthesis, structures, properties, processing, and applications. Hoboken: Wiley; 2010.

82. Nishida H. Thermal Degradation. In: Auras R, editor. Poly(lactic acid): synthesis, structures, properties, processing, and applications. Hoboken: Wiley; 2010

83. Signori $\mathrm{F}$, Coltelli MB, Bronco S. Thermal degradation of poly(lactic acid) (PLA) and poly(butylene adipate-co-terephthalate) (PBAT) and their blends upon melt processing. Polym Degrad Stab. 2009:94(1):74-82.

84. Garlotta D. A literature review of poly(lactic) acid. J Polym Environ 2001;9(2):63-84.

\section{Submit your manuscript to a SpringerOpen ${ }^{\odot}$ journal and benefit from:}

- Convenient online submission

- Rigorous peer review

- Immediate publication on acceptance

- Open access: articles freely available online

- High visibility within the field

- Retaining the copyright to your article

Submit your next manuscript at springeropen.com 